
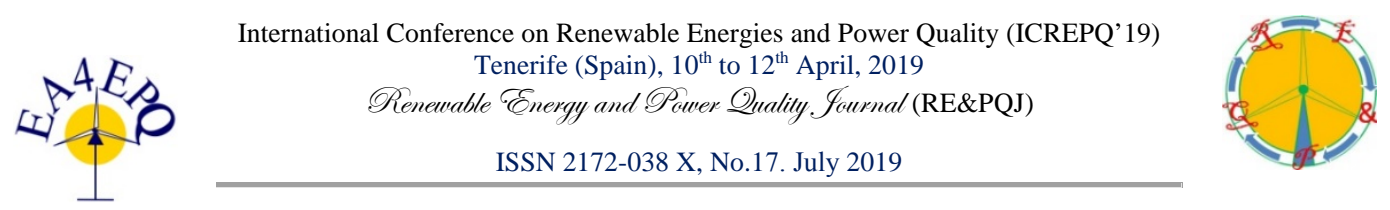

\title{
FEA Analysis and Optimization of Rotor Models in Permanent-Magnet Synchronous Motors fitted with Bonded Rare-Earth Magnets
}

\author{
V. Abad ${ }^{1 *}$, J. Sagredo ${ }^{1}$, J. Gonzalez ${ }^{1}$ \\ ${ }^{1}$ Electromechanical Department, Polytechnical School of Burgos University. Campus Vena \\ Avda. Cantabria S/N, Burgos, Spain \\ Phone number: +34 947259065, email: vaspol@ubu.es; jsgpol@ubu.es; jgv@ubu.es
}

\begin{abstract}
The Toyota Prius MG2 electric motor and its upgrades, since its first appearance in 1997, are presented in this paper. This electric motor has an Interior Permanent Magnet (IPM) fitted with Rare Earth (RE) magnets, which presents clear advantages over the more widely used Induction Motors (IM). The principal advantage is its high power-density value that makes it a leader in the Electric Vehicles (EV) market. This technology, however, faces a problem, in so far as the global production of RE magnets is an exclusive monopoly of China, (motivating the United States and Japan, among others, to investigate alternative systems). In this paper, the proposal is to substitute the sintered magnet in current use by the bonded type of magnet. The use of bonded magnets permits curved geometric forms, reducing the use of dysprosium, one of the most controversial elements of sintered magnets. These materials are compared using Finite Element Analysis (FEA) in the design of various rotor models including the proposal of a model with bonded magnetic materials, with the advantages of curved magnets and a dual layer arrangement. The proposed rotor model yielded a considerably higher power density than the model developed by Toyota.
\end{abstract}

\section{Keywords}

PMSM, Finite Element Analysis, Rare Earth Magnets.

\section{Toyota Prius MG2}

The Toyota Prius was presented on the Japanese market in 1997 and has since become most successful hybrid vehicle in the automotive sector with over 6 million global sales of vehicles up until the end of 2017 (60\% of Toyota hybrids) [1].

The Prius power system consists of an Internal Combustion Engine (ICE) and two electrical motors MG1 and MG2 shown in Figure 1. The MG1, on the left, mainly acts as a generator to charge the batteries and MG2, on the right, normally acts as a motor in combination with the ICE. The electric motor-generator is a three-phase permanentmagnet synchronous machine. The magnetic material was $\mathrm{NdFeB}$ and the stator and rotor core material was M19 steel.

The first Prius MG2 presented is shown in Figure 2.a. It used 8 poles with simple magnets of rectangular geometry with a 48-slot stator.

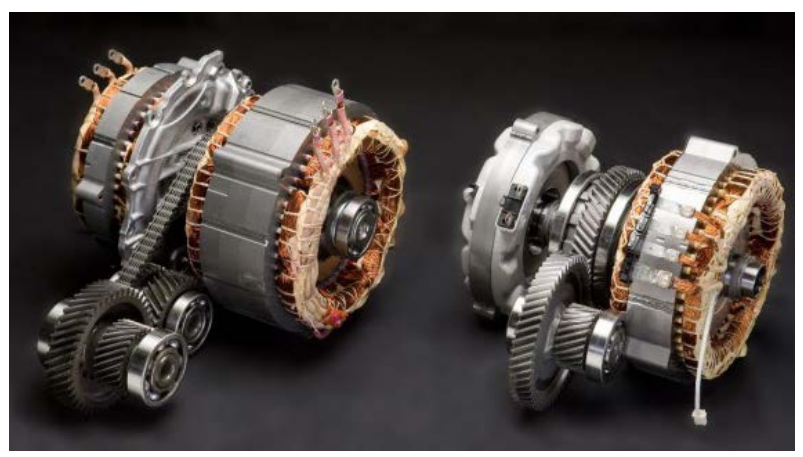

Figure 1. Ensemble MG1-MG2-Transaxle of 1997 (left) and 2004 (right) Toyota Prius.

In 2004, a new upgraded version, shown in the Figure 2.b, was presented with $2 \mathrm{~V}$ magnets per pole, leaving the rest of the stator and rotor almost completely intact.

In the 2010 version (Figure 2.c), the form of the poles hardly varies, maintaining the same configuration with $\mathrm{V}$ bar magnets, there was a reduction in the amount of material from 77 to 48 grams. Moreover, the modification of the mechanical properties duplicated the functional speed. The rotor had a shorter interior diameter and openings were included that reduced its weight and added mechanical strength.

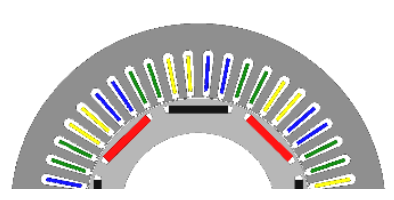

a )

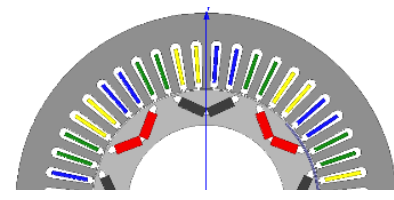

b)

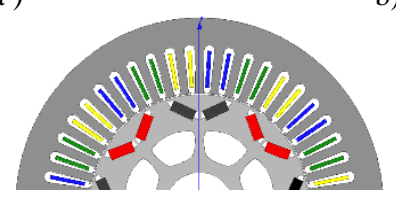

c)

Figure 2. Sections of Prius MG2 motors. a) 1997 model. b) 2004 model. c) 2010 model. 
The main characteristics and mechanical specifications of the motors are shown in Table I. Similar motors are used by Toyota in both the Lexus and the Camry models.

Table I. - MG2 Main Characteristics

\begin{tabular}{|l|c|c|c|}
\hline \multicolumn{1}{|c|}{ Year } & $\mathbf{1 9 9 7}$ & $\mathbf{2 0 0 4}$ & $\mathbf{2 0 1 0}$ \\
\hline Power (kW) & 33 & 50 & 60 \\
\hline Max Torque (Nm) & 350 & 400 & 207 \\
\hline Weight (kg) & 41 & 45 & 36,7 \\
\hline Magnetic Mass (kg) & 1.07 & 1.23 & 0.758 \\
\hline Length (mm) & 88.6 & 83.8 & 49.3 \\
\hline Power density (kW/kg) & 0.81 & 1.11 & 1.6 \\
\hline
\end{tabular}

\section{Magnetostatic torque curve and Prius 2004 model validation}

The magnetostatic torque curve was selected as a representative parameter of motor behavior, as it includes the magnetic torque, due to the flow rate (of the magnetic field), and the reluctance torque, due to the geometry of the motor, which our proposed model is intended to strengthen. In Eq. (1), the summands of both the magnetic torque and the reluctance torque can be appreciated in the calculation of the torque of a synchronous motor.

$$
T=\frac{3 p}{\omega} P=\frac{3 p}{\omega}\left[\frac{V_{t} E_{q}}{X_{d}} \sin \delta+\frac{\left(X_{d}-X_{q}\right) V_{t}^{2}}{2 X_{d} X_{q}} \sin (2 \delta)\right]
$$

First of all, we proceeded to validate the results of our FEA analysis with known data from the 2004 Toyota Prius MG2, using the magnetostatic torque curves obtained by [2] and [3]. This curve represents the motor torque for different rotor angles $(\delta)$ for three-phase DC voltages at a given point in time. Our results, shown in Figure 3, were all very similar, especially near the operating point.

The maximum torque was around $350 \mathrm{Nm}$ with 250 A of excitation and magnets with $B=1.026 \mathrm{~T}$ and $H_{c}=904.35$ $\mathrm{kA} / \mathrm{m}$.

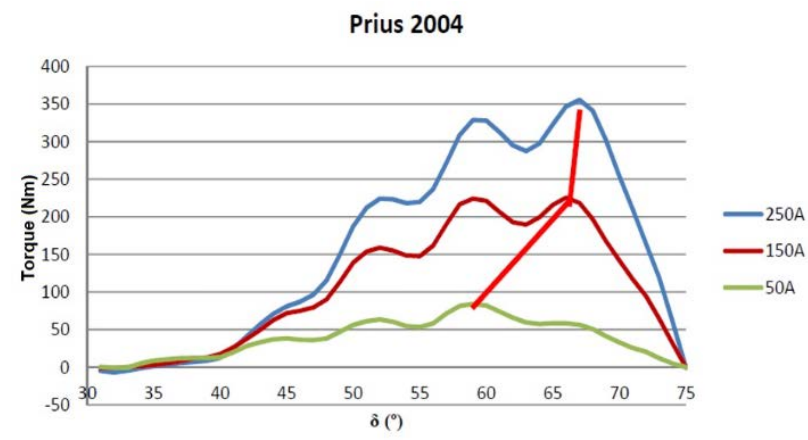

Figure 3. Magnetostatic torque curves of 2004 MG2 model.

The curve comprises $75-30=360 / 8=45^{\circ}$, corresponding to the mechanical rotation for one pole pair.

With the same idea of validating our model, we proceeded to evaluate the EMF speed values of the model and to compare them with the ORNL measurements in [4].
The results, depicted in Figure 4, showed very good accuracy, specially above $1,500 \mathrm{rpm}$ with a relative error below $8 \%$.

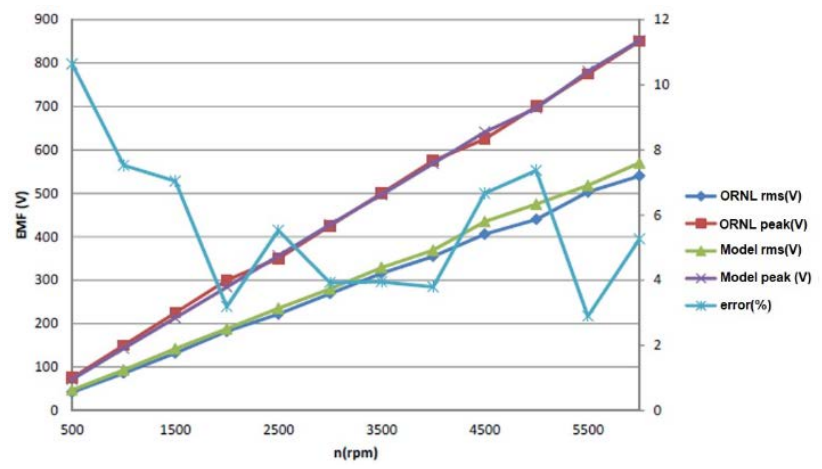

Figure 4. ORNL and proposed EMF model.

Finally, as shown in Figure 5, the magnetostatic torque can be decomposed into either the magnetic or the synchronous torque and the reluctance torque. The reluctance torque can be obtained by FEA analysis by suppressing the magnets from the model and repeating the magnetostatic analysis. Once this torque is obtained, the total curve can be subtracted to obtain the magnetizing torque.

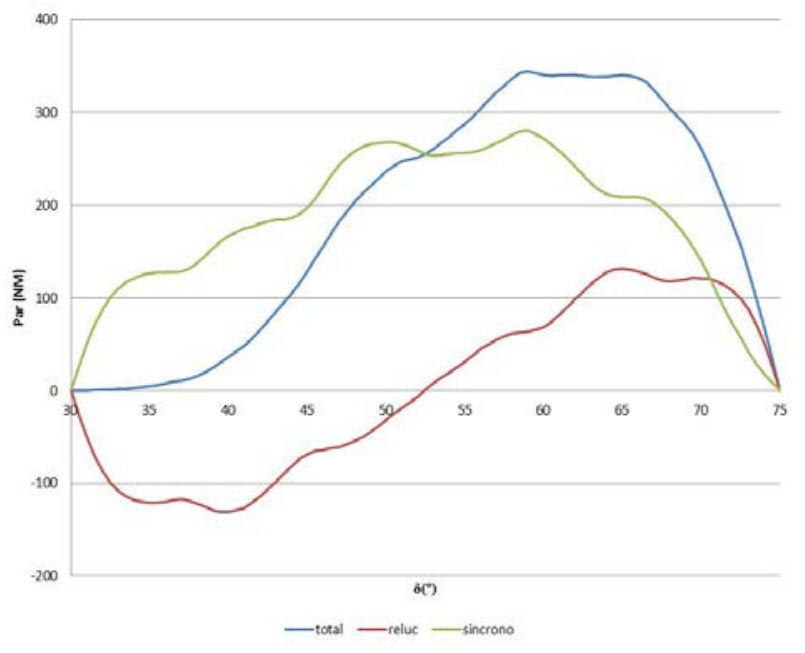

Figure 5: Decomposition of magnetostatic torque (blue) into synchronous (green) and reluctance (red) torques.

As may be seen, the reluctance torque curves, obtained from Equation (1), and the synchronous torque curves are equal and opposite for some time until they coincide at positive values.

\section{Study of other rotor magnet configurations}

When the Prius 2004 MG2 model and simulation environment was validated, we proceeded to study other magnet geometries and layouts and we contrasted the FEA magnetostatic torque values with our reference model. We maintained the same stator, excitation current, and main mechanical characteristics of the rotor, as indicated in Table II, in order to gain clear references for the geometrical effects on the torque. 
Table II. Common Rotor Characteristics

\begin{tabular}{|c|c|}
\hline Parameter & Value \\
\hline Rotor ext. diam.(mm) & 80.2 \\
\hline Bridge (mm) & 1.48 \\
\hline Bridge radius (mm) & 78.72 \\
\hline Length (mm) & 83.82 \\
\hline Poles & 8 \\
\hline Airgap (mm) & 0.7 \\
\hline Excitation current (A) & 250 \\
\hline
\end{tabular}

\subsection{Magnet geometries}

We modelled and simulated several magnet model set ups, including among others, rotors developed by DOE-UQM in Figure 6.a [7][8], with a single layer of 3 magnets. Other configurations were: double plain (Figure 6.b) based on a BMW patent [9] [10], V shape (Figure 6.c) and our proposal for a curved model (Figure 6.d), where an arrangement with an arced double layer yielded a higher torque value.

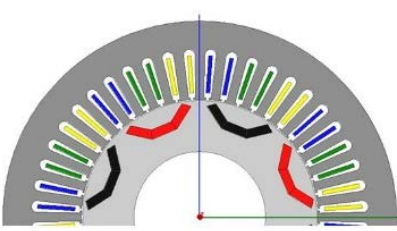

a)

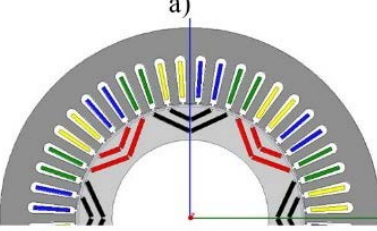

b)

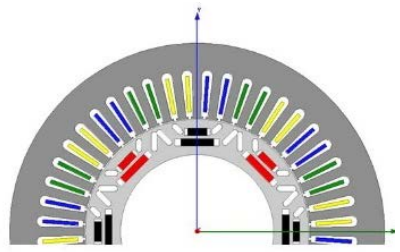

b)

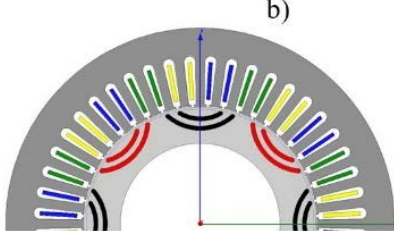

d)
Figure 6. Other developed rotor models. a) DOE-UQM. b) Plain Double Layer. c) V Shape Double Layer d) Arc Double layer.

In a comparison of models, the geometric parameters of the magnets in each model were converted into variables (e.g. length, thickness, distance between layers, etc.), and the maximum magnetostatic torque value were maximized using quasi-Newtonian optimization techniques and applied to FEA, as shown in Figure 7, for the Prius 2004 model.

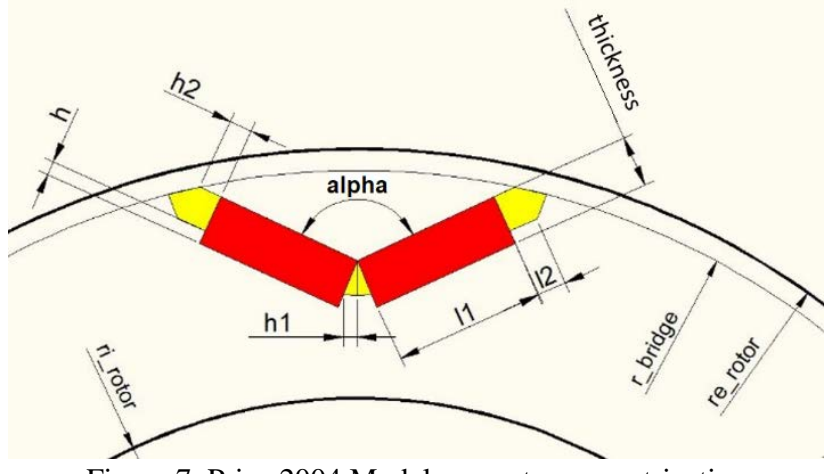

Figure 7. Prius 2004 Model magnets parametrization

The magnetostatic torque curves for simulated models are shown in Figure 8. All the models showed similar behaviors, with the max torque close to a rotor angle of $62^{\circ}$. The double layer model has no negative torque value in the first $30^{\circ}$, unlike the 2004 model. These results show that our proposed rotor model, arc double layer (in red in the figure), obtained the highest max torque values under the same conditions as the other.

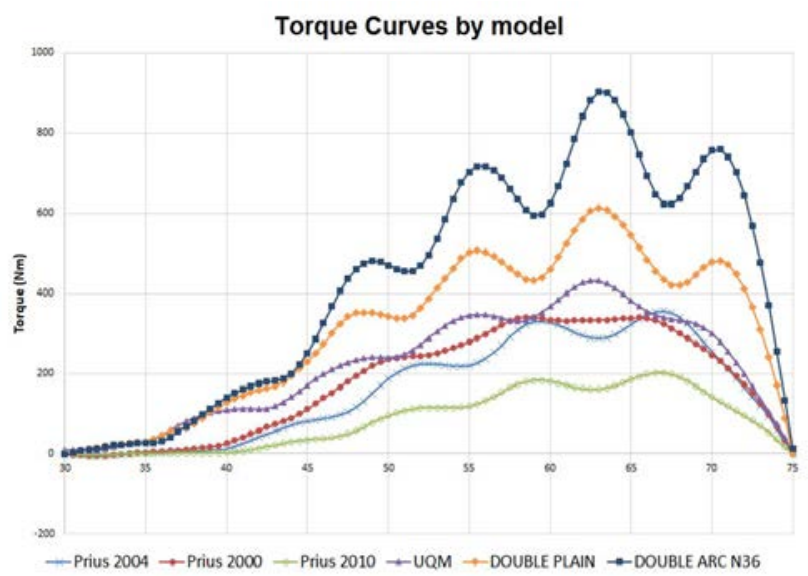

Figure 8. Magnetostatic torque curves of the models under study.

As can be seen in Figure 9, the optimum solution of the torque in the double layer models showed strong "peaks" every $7.5^{\circ}$, corresponding with the stator teeth separation angle (360\% $/ 48$ slots). At those points, the optimization process matched both layers of magnet endings with the stator slot holes.

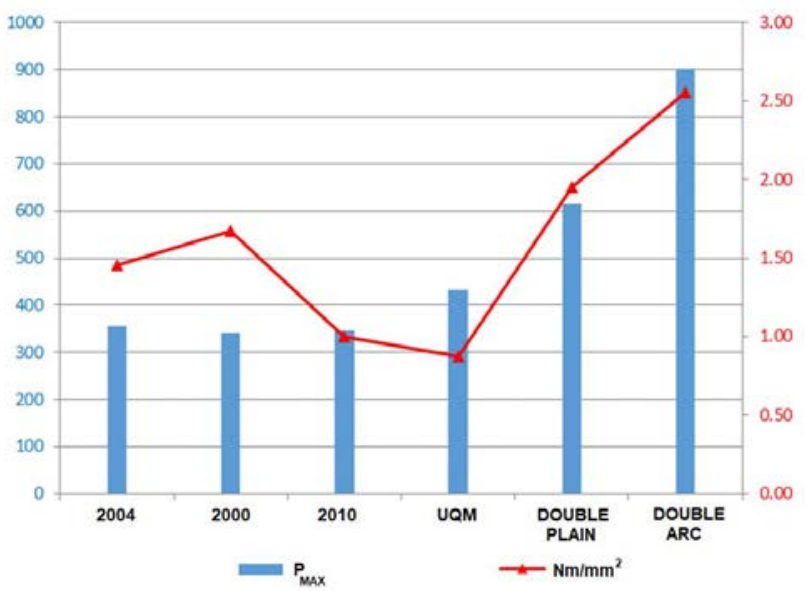

Figure 9. Max torque (blue) and max torque/area (red) values for simulated models.

A comparison with the 2004 MG2 model gives us an idea of the magnet area that is needed to obtain the same max torque (350 Nm) for each simulated geometry. The results, in Figure 9, indicated that, as we expected, the Prius 2000 model, with flat poles and an initially smaller pair, required the most material: 52\% more than the 2004 model with the $\mathrm{V}$-poles. The other double layer models under study either exceeded or equaled the behavior of the reference model, because the double layer considerably increased the reluctance torque. The arc double layer, with a magnet thickness of $1.3 \mathrm{~mm}$, was the least amount of material required (40\% of the area of the 2004 model). 


\section{Sintered and Bonded RE magnets}

Currently most rotor designs of IPM motors employ sintered permanent magnets, combining the high coercivity of the hard phase with the high remanence of the soft phase, achieving a high value of maximum energy of up to 52 MGOe. Their disadvantage is that their characteristics are quickly degraded when the operating temperature rises. This effect can be compensated by the addition of dysprosium that stabilizes the fall of the coercivity, although its cost is prohibitive and continues to rise.

There have been substantial improvements to bonded magnets over recent years. One consequence is our proposal of the double layer arc magnet model, yielding a value in excess of the maximum torque of all the other models under study, principally due to the increase in reluctance torque.

The proposed magnets have a very similar composition to the above, although their manufacturing process differs. The latest innovations in the field of anisotropic powder can produce magnets that reach the energy values of the sintered magnets, as described in [4], [5] and [6].

As the bonded magnets can be directly injected onto the rotors, thinner magnets than the sintered models may be used. Likewise, as the amount of agglomerant increases, problems of corrosion and fragility common to the sintered magnets may be avoided.

In Figure 10, it may be appreciated that the curve for NB$10 \mathrm{H}$ shows a maximum torque that reaches a value of 600 $\mathrm{Nm}$ and is close to the values provided by the N36 magnets.

Sintered/Bonded

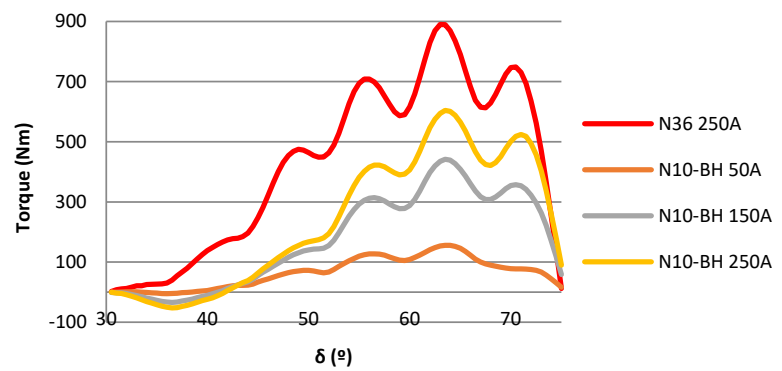

Figure 10. Magnetostatic torque curve models for sintered (N36) and bonded (NB-10H) magnets.

Another advantage of the bonded magnets is that their lower value of coerciveness presents a lower cogging torque (see Figure 11), lengthening the life of the motors, as the cogging torque causes vibrations and noise that negatively affect the life of the motor.

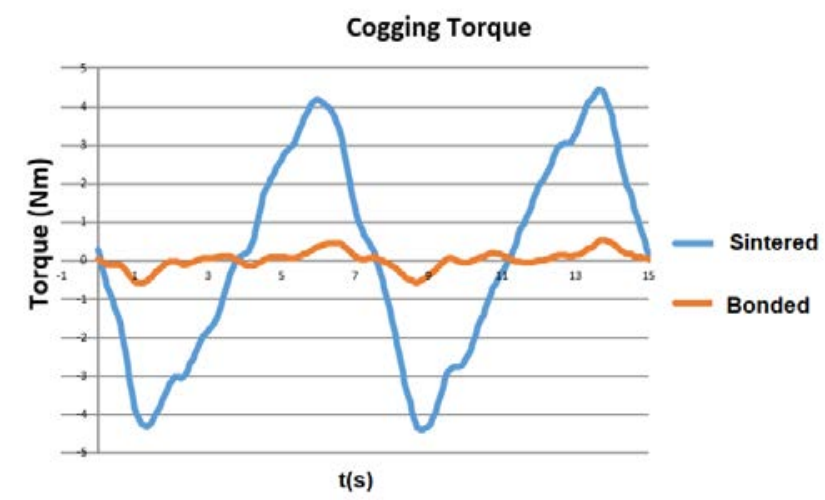

Figure 11. Cogging torque for sintered and bonded magnets

\section{Other aspects of the curved model.}

\subsection{Arc-double layer Model. Endings of the magnets}

Our proposed rotor model, with the highest max torque, consists of a double layer of circular arc magnets and is a model for further in-depth development, considering more specific aspects of the geometry. In the first place, we studied the end shapes of the magnets and proposed the following 3 types of endings:

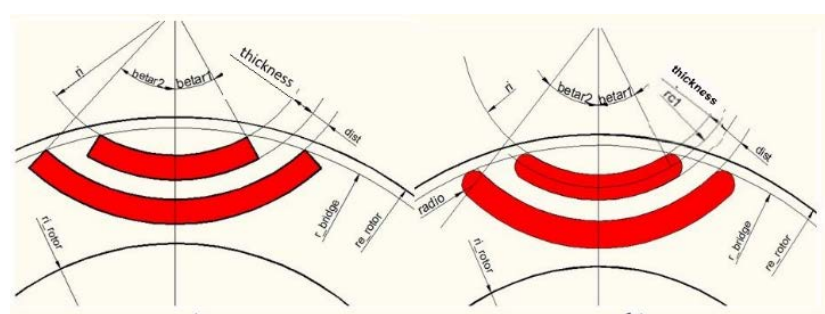

a)

b)

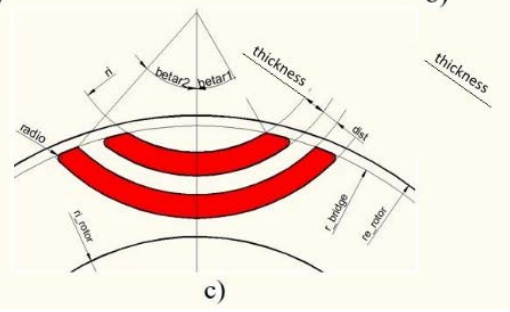

Figure 12. Proposed endings of the arc magnets. a) straight b) rounded c) wings

It appears that the wing endings, due to their effect on the flux path (Figure 13), facilitated an increase in the maximum torque values, by as much as $850 \mathrm{Nm}$. 


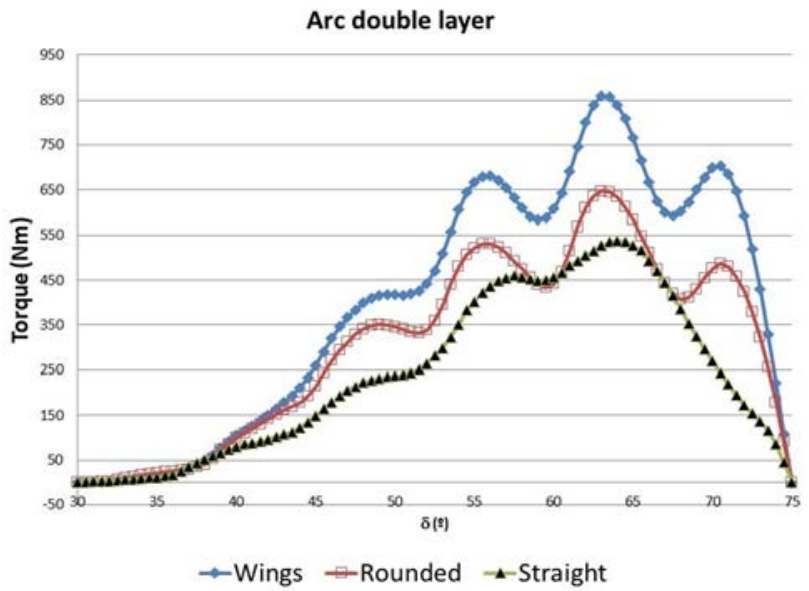

Figure 13: Magnetostatic torque for different magnet endings.

The model with the straight endings provided the weakest torque, as the magnets have a smaller surface, for the same radius of curvature, separation and thickness. The significant effect of the ending shapes can be seen in the shape of the torque curves and their maximum values.

Again, the effect of the angle (360\% $/ 48$ slots) may be seen. At those points, the optimization process matched the endings of both layers of magnets with the stator slot holes. Further improvements could be introduced to level those peaks, so that the endings are more closely aligned with the stator slots.

\subsection{Magnetization Direction of the Magnets}

Another effect of the magnets to be considered is magnetization direction. As with the plain magnets of the Prius 2004 model, the magnetization lines were usually transversally parallel to the magnet. The effect is shown in Figure14.a and is named diametral magnetization. With arc magnets, the magnetization direction can also be "radial", as shown in Figure 14.b, normally using the center of the arc as the center or the magnetization direction.
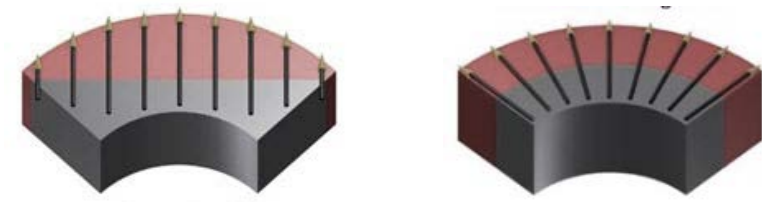

Figure 14. a) Plain/Diametral Magnetization b) Radial magnetization

In Figure 15, the effect of the magnetization direction on the potential vector can be appreciated. Simulation results on differences in magnetization direction indicated that for low currents (50 A) there was no significant difference in torque values. At currents close to the maximum value of $250 \mathrm{~A}$, the torque value reached $900 \mathrm{Nm}$ for radial magnetization, at less than 6\%, higher than the $850 \mathrm{Nm}$ with diametral magnetization. It may therefore be considered that the complexity of radial direction magnetization in the magnets in no way compensated the increased torque that was achieved.

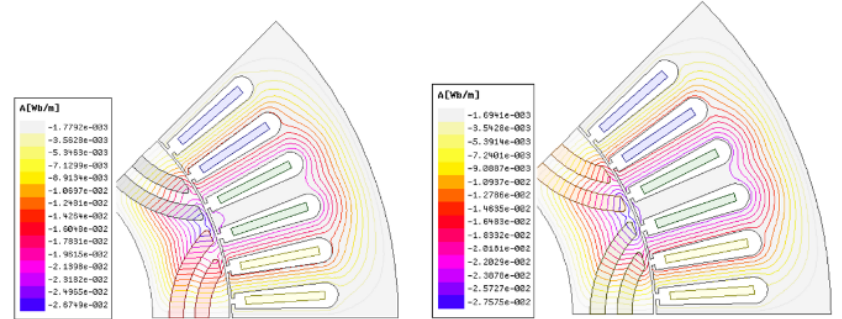

Figure 15. Magnetization simulation of differences in the potential vector with different magnetization directions.

\section{Results and conclusions}

In the study that has been presented, a comparative study has first been conducted on the different rotor models of the IPMSM model, looking principally at the characteristic magnetostatic torque. The analysis has also contemplated other parameters such as EMF, cogging torque, noise indicator and vibrations and the breakdown of the torque that allows us to analyze its increase at the expense of reluctance torque with no need to increase the magnetic material.

The use of a bonded magnetic material has been proposed, currently under development, for the design of a magnet with a geometric curve that is more difficult with sintered materials. At present, there are only a few bonded magnets currently used in small window-winder motors.

The proposed arc-double layer magnets with wing endings represent a feasible proposal for an IPM rotor, achieving a high maximum magnetostatic torque, even using RE bonded magnets, which have $20 \%$ less average magnetic energy than the sintered magnets, normally used by EVH motors such as Toyota Prius. In Table III, a comparison of the Prius 2004 rotor and our "Arc Double Layer” model is presented.

Table III.- MG2 Prius 2004 and Proposed Model Data Comparison

\begin{tabular}{|c|c|c|}
\hline & $\begin{array}{c}\text { Arc- } \\
\text { double layer }\end{array}$ & $\begin{array}{c}\text { Prius } \\
2004\end{array}$ \\
\hline Magnets area $\left(\mathrm{mm}^{2} / \mathrm{pole}\right)$ & 353.04 & 244.9 \\
\hline Magnets Weight(kg) & 1.42 & 1.23 \\
\hline Rotor Weight $(\mathrm{kg})$ & 4.95 & 5.38 \\
\hline Stator Weight $(\mathrm{kg})$ & 16.47 & 16.47 \\
\hline Copper Weight $(\mathrm{kg})$ & 4.93 & 4.93 \\
\hline Total Weight $(\mathrm{kg})$ & 44.76 & 45.00 \\
\hline Max Torque $(\mathrm{Nm})$ & 600 & 400 \\
\hline Power $(\mathrm{kW})^{*}$ & 75 & 50 \\
\hline Specific Power $(\mathrm{kW} / \mathrm{Kg})$ & 1.67 & 1.11 \\
\hline Specific Density $(\mathrm{kW} / \mathrm{l})$ & 4.87 & 3.25 \\
\hline
\end{tabular}

At the time of manufacturing the rotor, if bonded material is used, the gap between magnet and rotor can subsequently be filled and magnetized, thereby avoiding loose fitting problems when having to be inserted.

The curved magnet model that has been presented has a basic optimized design to achieve the maximum magnetostatic torque value, but it can be refined with some 
details so that, even if some of the maximum torque is sacrificed, its losses and other practical aspects can be studied and improved. For example, their lighter weight permits higher motor rotation speeds, a clear tendency of the manufacturers. The thickness of the bridge [11] can also be reduced in the design, thereby limiting the mechanical stresses.

The main possible modifications to the model are as follows:

- The inclusion of dispersion flow barriers by attaching non-magnetic materials to the endings of the magnets.

- Magnets of different thicknesses.

- Lowering the angle covered by the magnets of the 2nd layer to flatten the area of maximum torque and to widen its radius of curvature.

- The inclusion of other non-magnetic barriers to conduct the magnetic flux.

- An increased number of poles that favor the use of agglomerated magnets.

Another objective function could be established such as relative density and continued improvements to the ratio between reluctance and magnetic torque.

\section{References}

[1] Toyota Global Newsroom. "Hybrid Model Global Sales Results".https://newsroom.toyota.co.jp/en/corporate/compan yinformation/hybridsales/. Last access December 2018.

[2] Hsu, J., C. Ayers, and C. Coomer, Report on Toyota/Prius motor design and manufacturing assessment. 2004: United States. Department of Energy.

[3] Efficiency, E. and R. Energy, Evaluation of the 2010 Toyota Prius hybrid synergy drive system. 2011.

[4] Efficiency, E. and R. Energy, Evaluation of 2004 Toyota Prius hybrid electric drive system. 2006.

[5] Kaczmarek, R., Simulating the Toyota Prius electric motor. 2012, Cobham Technical Services.

[6] Abad, V. Sagredo J. "Evolución y proceso de fabricación de imanes "NEO" aplicados a motores de vehículos eléctricos." Revista de Metalurgia 54.3 (2018): 127.

[7] Hendershot, J., MotorSolve analysis of the 2010 Toyota Prius Traction Motor. 2015.

[8] Ley Josh, L.J., FreedomCAR Advanced Traction Drive Motor Development Phase I. UQM Technologies. Oak ridge National Laboratories, 2006: p. 84.

[9] Merwerth, J., J. Halbedel, and G. Schlangen, Electrical drive Widmer, J.D., R. Martin, and M. Kimiabeigi, Electric vehicle traction motors without rare earth magnets. Sustainable Materials and Technologies, 2015. 3: p. 7-13.

[10] Honkura, Y., Automotive motor innovation with anisotropic bonded magnet-MAGFINE. Journal of Iron and Steel Research, International, 2006. 13: p. 231-239.

[11] Kamiya, M., Development of traction drive motors for the Toyota hybrid system. IEEJ Transactions on Industry Applications, 2006. 126(4): p. 473-479. 